Ciência e Natura, Santa Maria, v. 37 n. 4 set-dez. 2015, p. 160-170

Revista do Centro de Ciências Naturais e Exatas - UFSM

ISSN impressa: 0100-8307 ISSN on-line: 2179-460X

\title{
ciênciaenatura
}

\section{BALANÇO HÍDRICO MENSAL PARA DOIS MUNICÍPIOS DO ESTADO DA PARAÍBA}

\author{
Monthly hydric balance for two municipalities of Paraíba's state
}

Maytê Duarte Leal Coutinho ${ }^{1}$, Micejane da Silva Costa ${ }^{1}$, Allan Rodrigues Silva ${ }^{1}$, Thalyta Soares dos Santos ${ }^{1}$, Ana Carla dos Santos Gomes ${ }^{1}$, Michelyne Duarte Coutinho de Morais ${ }^{2}$, Priscila Valdênia dos Santos ${ }^{1}$

\author{
Programa de Pós-Graduação em Ciências Climáticas - PPGCC, Universidade Federal do Rio Grande do Norte - \\ PPGCC/UFRN, Brasil \\ ${ }^{2}$ Instituto Nacional de Pesquisas Espaciais, INPE, Brasil
}

\section{RESUMO}

Esta pesquisa teve como objetivo analisar o comportamento mensal do Balanço Hídrico Climatológico (BHC) em dois diferentes municípios da Paraíba (PB): um no município de Alhandra, localizado na zona costeira do estado da PB e outra localizada no município de Prata. A metodologia utilizada para o cálculo do BHC foi proposto por Thornthwaite e Matter (1957) com modificações Krishnan (1980). Os resultados mostraram que o período chuvoso se concentra nos meses de (maio a julho) em Alhandra e no município de Prata, nos meses de (fevereiro a abril) correspondendo a cerca de $50 \%$ do total anual. Com relação ao BHC, os resultados obtidos mostraram limitações dos recursos hídricos, principalmente no município de Prata. Foi verificado que este município apresentou nove meses de déficit hídrico. Afetando assim, negativamente o desenvolvimento das culturas. Indicando desta maneira, que o município de Prata será insuficiente para atender às necessidades básicas do solo, vegetação e da sociedade.

Palavras-chave: Variabilidade, déficit hídrico, recursos hídricos, demanda hídrica.

\begin{abstract}
This research aimed to analyze the monthly behavior of the Water Balance Climatological (WBC) in two different cities of Paraíba (PB): one in the city of Alhandra, located on the seafront of the PB state and the other located in the municipality of Prata. The methodology used for calculating the WBC was proposed by Thornthwaite and Matter (1957) with modifications Krishnan (1980). The results showed that the rainy season is concentrated in the months (May-July) in Alhanbra and Prata municipality in months (February to April) corresponding to about 50\% of the annual total. Regarding the WBC, the results showed limitations of water resources, especially in the municipality of Prata. It was found that this city had nine months of drought. Thus affecting adversely the development of crops. Thus indicating that the Silver municipality will be insufficient to meet the basic needs of the soil, vegetation and society.
\end{abstract}

Key-words: Variability, drought, water resources, water demand. 


\section{INTRODUÇÃO}

Vários fatores afetam as culturas, os principais são a disponibilidade hídrica e a temperatura. A variação destes fatores tem influência direta na duração do ciclo das culturas e no desenvolvimento de seus subperíodos e, conhecê-los é um importante passo para o alcance de maiores produtividades (Fenner et al., 2014). Conforme mostram os estudos de Marini et al., (2012) e Heinemann e Stone (2009), as irregularidades na distribuição das chuvas resultam no aumento do risco para o cultivo, pois a distribuição das chuvas durante o ciclo das culturas são limitantes a produção. De forma que há necessidade de planejamento e técnicas que permitam conhecer o regime hídrico e definir estratégias agrícolas.

O planejamento agrícola e tomadas de decisão que otimizem a produção e o uso da água são fundamentais para o desenvolvimento de uma região. Dentre as medidas que podem ser tomadas tem-se o cálculo do Balanço Hídrico Climatológico (BHC), que segundo Santos et al., (2010) é uma ferramenta de auxílio ao planejamento agropecuário. Seu uso permite definir as características do regime climático de uma região, tornando-se uma ferramenta de auxílio ao zoneamento agroclimático.

O BHC é uma primeira avaliação hídrica de uma região. Com este é possível determinar a contabilização da água em determinada camada do solo, onde se definem os períodos secos (deficiência hídrica) e úmidos (excedente hídrico) de um determinado local (Reichardt, 1990), assim, identificando as áreas onde as culturas podem ser exploradas com maior eficácia. Segundo (Pereira et al., 2002) o BHC é a contabilização da água do solo, resultante da aplicação do princípio de conservação de massa em um volume de solo vegetado. A variação do armazenamento de água no volume considerado ( $\triangle \mathrm{ARM})$, por intervalo de tempo, representa o balanço entre o que entrou e o que saiu de água dentro do volume de controle.

Ainda de acordo com Pereira et al.,(2002), os principais componentes do BHC para definir a demanda e disponibilidade hídrica são: precipitação (P), evapotranspiração real (ETR), evapotranspiração potencial (ETP), armazenamento de água no solo (ARM), deficiência hídrica (DEF) e excedente hídrico (EXC). O balanço pode ser realizado tanto na atmosfera como na superfície da terra, no solo ou, ainda, no sistema terra-atmosfera. Na atmosfera, o balanço é composto pelas variáveis: água precipitável (armazenamento de água na atmosfera), precipitação, convergência do fluxo de umidade atmosférico e pela evaporação. Em escala climatológica, o ciclo hidrológico de uma grande bacia requer as mesmas variáveis atmosféricas, assim como a água armazenada na bacia e a divergência do escoamento superficial.

A região Nordeste do Brasil (NEB) sofre constantemente com a escassez de água. Porém, em algumas regiões, o problema não é o total anual de precipitação pluviométrica que em média é elevado, e sim, a anormalidade da distribuição da mesma durante o ano. A análise do BHC em regiões distintas do NEB explica-se devido à necessidade da racionalidade no uso dos recursos hídricos.

É interessante realizar esta análise em anos-padrão como forma de analisar a dinâmica atmosférica, esse tipo de análise teve início nas concepções de Monteiro (1973), ao propor critérios para a escolha de anos-padrão, executando a análise rítmica, levando em conta a concepção sorreana do clima. Os anos considerados excepcionais ditos secos ou chuvosos devem corresponder aos períodos em que trouxeram impactos tanto sociais, quanto 
econômicos, tanto pela falta, quanto pelo excesso de chuva. Por tais motivos é que se avalia esse processo de escolha como sendo uma etapa importante e que podem ser auxiliados através da utilização de técnicas tanto qualitativas quanto quantitativas (Schneider e Silva, 2013).

Diante do exposto, objetivou-se nesta pesquisa analisar o comportamento mensal da precipitação pluviométrica e temperatura do ar para duas regiões distintas do estado da Paraíba (PB), uma no município de Alhandra, localizado na zona costeira do estado da PB, e outra localizada no município de Prata no cariri. Bem como, realizar cálculos do BHC com o intuito de conhecer a variação da água no solo em dois municípios da PB.

\section{MATERIAL E MÉTODOS}

\subsection{Região de estudo e dados}

O município de Prata está localizado sobre a microrregião do Cariri Ocidental, predomina o clima semiárido quente (classificação de Köppen). As chuvas são escassas e mal distribuídas, são mais frequentes no verão, nos meses de janeiro a abril, período denominado inverno na região, a precipitação pluviométrica média anual no município é inferior a $800 \mathrm{~mm}$ e temperatura média de $24,8{ }^{\circ} \mathrm{C}$ (Albuquerque et al., 2012). Em Alhandra, o clima é do tipo tropical chuvoso com verão seco. Da classificação de Köppen, apresenta as seguintes características: quente e úmido, com chuvas do outono ao inverno; média térmica anual superior a $20{ }^{\circ} \mathrm{C}$ (em média $26^{\circ} \mathrm{C}$ ); média das máximas em torno de $28^{\circ} \mathrm{C}$ (entre fevereiro e março); média das mínimas em torno de $23^{\circ} \mathrm{C}$ (entre julho e agosto); amplitude média anual em torno de $5{ }^{\circ} \mathrm{C}$; e totais pluviométricos entre 1.200 e $1.800 \mathrm{~mm}$ (LIMA \& HECKENDORFF, 1985).

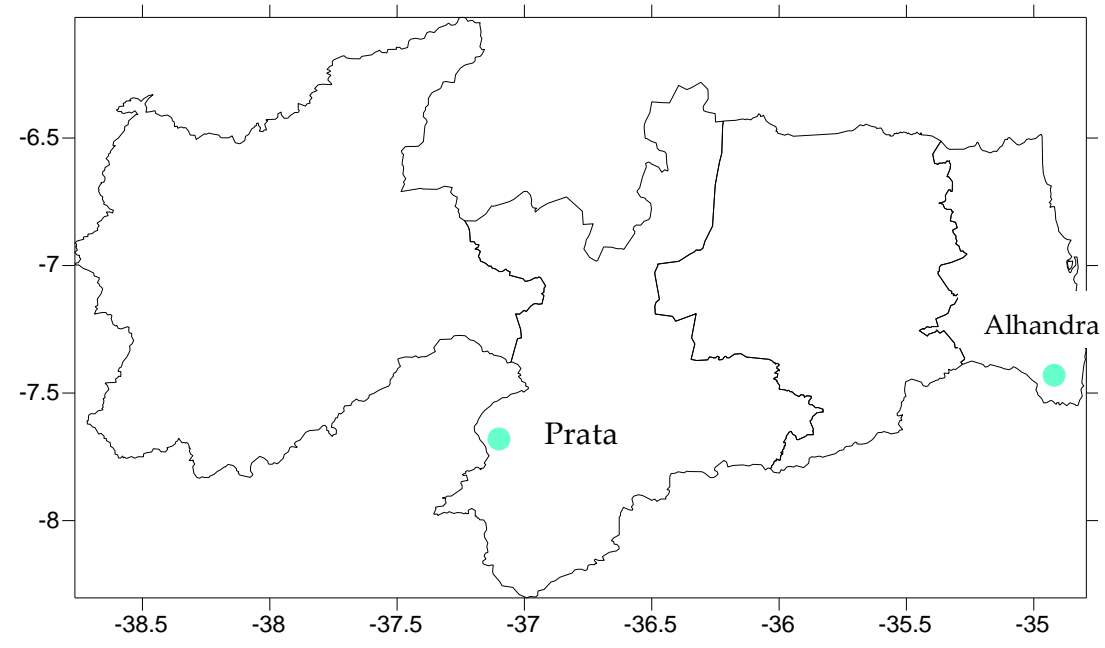

Figura 1. Localização da área de estudo no estado da Paraíba.

Nesta pesquisa, utilizamos dados observados de precipitação mensal da cidade de Alhandra e Prata do estado da Paraíba para o período de 1966 a 2003, cedido pela Unidade Acadêmica de Ciências Atmosféricas (UACA) da Universidade Federal de Campina Grande (UFCG). Os dados da máxima capacidade de retenção de água disponível pelo solo foram oriundos da Empresa Brasileira de Pesquisa Agropecuária Centro de Pesquisa de Solo (EMBRAPA), unidade em Recife. Como os dados de temperatura do ar são mais escassos e difíceis de serem obtidos quando comparados aos dados de TSM, os cientistas que monitoram o clima da Terra usam a TSM em substituição à temperatura do ar, assumindo que as duas temperaturas aumentam e diminuem proporcionalmente, como nos estudos de Cavalcanti e Silva (1994). 
Desta maneira, foram obtidas estimativas médias mensais da temperatura do ar para o período de janeiro de 1966 a dezembro de 2003 através do software Estima-T, desenvolvido por Cavalcanti et al.,(2006). Este programa computacional tem como entrada: anomalia de TSM dos oceanos Atlântico e Pacífico tropicais obtidas junto ao NOAA (2003), latitude, longitude e a altitude do local. Segundo Cavalcanti et al., (2006).

$T_{j n}=a_{0}+a_{1} \lambda+a_{2} \varphi+a_{3} h+a_{4} \lambda^{2}+a_{5} \varphi^{2}+a_{6} h^{2}+a_{7} \lambda \varphi+a_{8} \lambda h+a_{9} \varphi h+$ ATSM $_{j n}$ (1)

Sendo $\varphi$ é a latitude (graus), $\lambda$ é a longitude (graus), h é a altitude da estação meteorológica em $(\mathrm{m}), a_{0}, a_{1} \ldots a_{9}$ são os coeficientes de regressão e $j, n$ indicam o mês e o ano, respectivamente, para o qual está sendo calculada a temperatura do $\operatorname{ar}\left(T_{j n}\right)$.

\subsection{MÉTODOS}

\subsubsection{Balanço Hídrico Climatológico}

O BHC foi calculado com um programa elaborado por (Rolim et al., 1998), no qual utiliza a metodologia de Thornthwaite e Mather (1957) com as modificações de Krishnan (1980). Para tanto, utilizou-se dados mensais de temperatura do ar, precipitação pluviométrica, coordenadas geográficas, altitude e Capacidade de Água Disponível (CAD), definida como o armazenamento máximo de água no solo, o qual foi considerado o valor de $140 \mathrm{~mm}$ para o município de Alhandra/PB e $85 \mathrm{~mm}$ para Prata/PB.

O cálculo da ETP foi realizado pelo método de Thornthwaite (1948):

$$
E T P=C_{j} .1,6\left(\frac{10 . T}{I}\right)^{a}
$$

Sendo ETP $=$ Evapotranspiração Potencial; $\mathrm{C}_{j}=$ Fator de ajuste em função da latitude e mês do ano; $\mathrm{T}=$ Temperatura média mensal $\left({ }^{\circ} \mathrm{C}\right) ; I=$ Índice de calor anual.

O índice de calor anual é calculado pela seguinte equação:

$$
I=\sum_{1}^{12}\left(\frac{T}{5}\right)^{1,514}
$$

O valor de $a$ é dado pela função cúbica do índice anual:

$$
a=6,75 \times 10^{-7} \cdot I^{3}-7,71 \times 10^{-5} \cdot I^{2}+1,7292 \times 10^{-2} \cdot I+0,49239
$$

Os valores obtidos pela fórmula de Thornthwaite são válidos para meses de 30 dias com 12 horas de luz solar por dia. Como o número de horas de luz por dia muda com a latitude e também porque há meses com 28 e 31 dias, torna-se necessário proceder a correções. Este fator de correção $\left(C_{j}\right)$ é obtido da seguinte forma:

$$
C_{j}=\frac{h}{12} \times \frac{j}{30}
$$

Sendo $h$ representa horas de luz solar por dia e $j$ mês.

\section{RESULTADOS E DISCUSSÃO}

\subsection{Variabilidade mensal da Precipitação}

Os resultados mostram que existe uma grande variação entre a média anual de precipitação pluviométrica entre os dois municípios. Conforme mostra a Figura 2, verifica-se uma média 
anual de precipitação pluviométrica foi de $1991 \mathrm{~mm}$ para o município de Alhandra e de 646 mm para o município de Prata.

No município de Alhandra, as chuvas concentram-se nos meses de maio, junho e julho e no município de Prata, concentram-se em fevereiro, março e abril correspondendo a cerca de $50 \%$ do total anual. Verifica-se valor máximo de precipitação em Alhandra no mês de junho (329 mm) e mínimo em outubro $(50 \mathrm{~mm})$. No município de Prata, o valor máximo de precipitação é no mês de março $(159 \mathrm{~mm})$ e o valor mínimo em setembro $(4 \mathrm{~mm})$. Segundo (Molion e Bernardo, 2002) as chuvas da região da zona costeira da Paraíba são beneficiadas pelas brisas terrestres e marítimas, explicando em parte, essa grande variação entre os valores no agreste e na zona costeira do estado. Em contrapartida, o semiárido paraibano é caracterizado por baixas médias pluviométricas e altos índices de evapotranspiração, e que a distribuição pluviométrica se dá em um período muito curto do ano, com uma distribuição temporal e espacial bastante irregular (Neto et al., 2007). De acordo com Nicholson (1999), um dos problemas agravados pelas estiagens nas regiões semiáridas é a expansão dos núcleos de desertificação. Os fenômenos meteorológicos que contribuem para a desertificação são, por ordem de importância, as secas, as avalanches, a erosão do vento e a variabilidade climática (Neto et al., 2007).

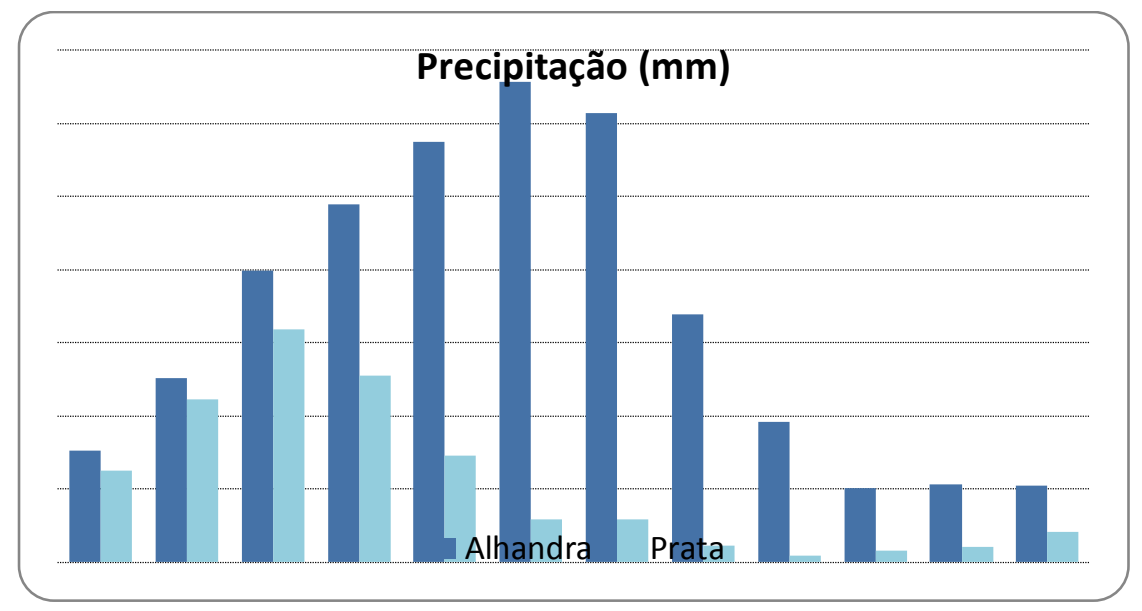

Figura 2. Totais mensais médio da precipitação pluviométrica $(\mathrm{mm})$ durante o período de 1966 a 2003 para os municípios de Prata e Alhandra.

\subsection{Variabilidade mensal da Temperatura do ar}

Os valores médios de temperatura para as duas localidades analisadas estão apresentadas na Figura 3, na qual é possível observar que nos dois municípios as médias apresentaram grandes variações.

As médias da temperatura nos municípios apresentaram variações de 21 a $25^{\circ} \mathrm{C}$ em Prata e de 23 a $26^{\circ} \mathrm{C}$ em Alhandra para o período em estudo. Com menores e maiores médias de temperatura no município de Prata no mês de julho e dezembro, respectivamente. Em Alhandra, observou-se valor mínimo em julho e máximo de (novembro a abril). Estudos sobre o conhecimento da variação da temperatura de cada local são de extrema importância. Em relação às atividades agrícolas, esta variável auxilia no manejo de culturas, pois esta tem influência sobre o desenvolvimento vegetal, no qual cada espécie tem respostas específicas às variações de temperatura. Segundo Albrecht et al., (1986) e Dias et al., (2011) uma ótima temperatura para a germinação da maioria das culturas tropicais e subtropicais varia entre 26,5 e $30^{\circ} \mathrm{C}$. 


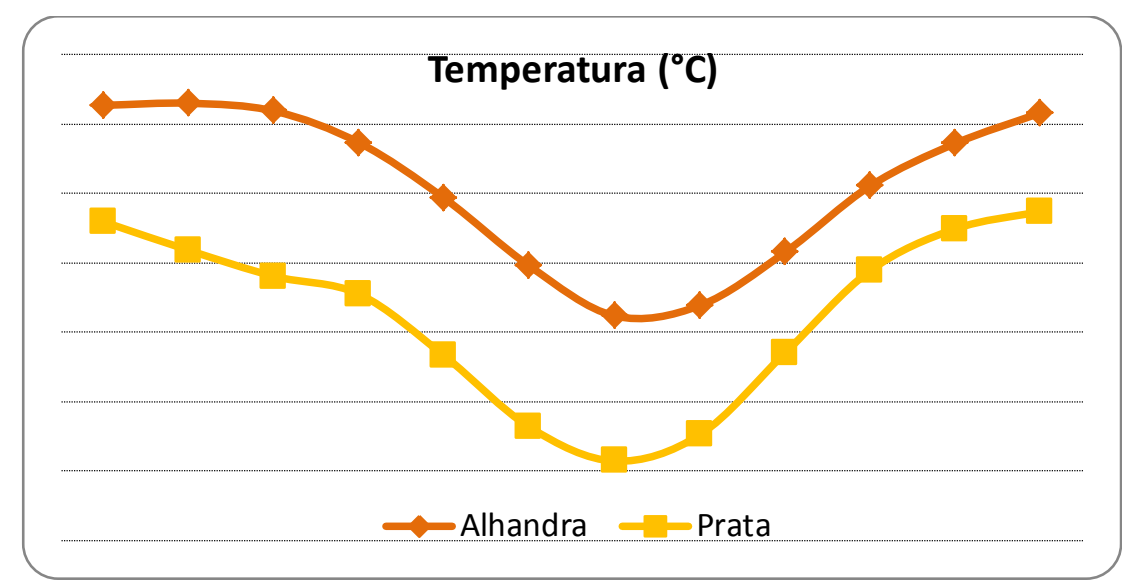

Figura 3. Totais mensais da temperatura do ar em $\left({ }^{\circ} \mathrm{C}\right)$ durante o período de 1966 a 2003 para os municípios de Prata e Alhandra.

\subsection{Balanço Hídrico Climatológico}

Para uma melhor visualização da variação dos dados mensais de P, ETR e ETP, no período de 1966 a 2003, foi construído o gráfico da Figura 4, a partir das Tabelas 1 e 2.

Conforme mostra a Figura 4, verifica-se que no município de Prata os menores valores de ETP são nos meses mais chuvosos (junho, julho e agosto), na ordem de aproximadamente $75 \mathrm{~mm}, 72 \mathrm{~mm}, 77 \mathrm{~mm}$, respectivamente, e valor máximo de $121 \mathrm{~mm}$ no mês de dezembro, com total médio anual na ordem de $1160 \mathrm{~mm}$ e média anual de $97 \mathrm{~mm}$. Enquanto no município de Alhandra/PB, observa-se um total médio anual de ETP $1393 \mathrm{~mm}$, com valor máximo em torno $139 \mathrm{~mm}$ no mês de dezembro, e valor mínimo de $88 \mathrm{~mm}$ no mês de julho.

Nota-se que em Prata, ocorre um aumento gradual da precipitação de janeiro a março, logo após, ocorrendo um decréscimo gradual de março até dezembro. Em Alhandra, o aumento é de janeiro a julho, com decréscimo de julho até dezembro. A curva de ETR mostra um aumento significativo de janeiro a março nos dois municípios com decréscimos concentrados em três períodos para Alhandra: de Março a julho, de agosto a setembro e outubro a dezembro de forma mais significativa e em Prata, observa-se um decréscimo entre abril e novembro. Com valores anuais de ETR em torno de $1223 \mathrm{~mm}$ e $638 \mathrm{~mm}$ em Alhandra e Prata, respectivamente.
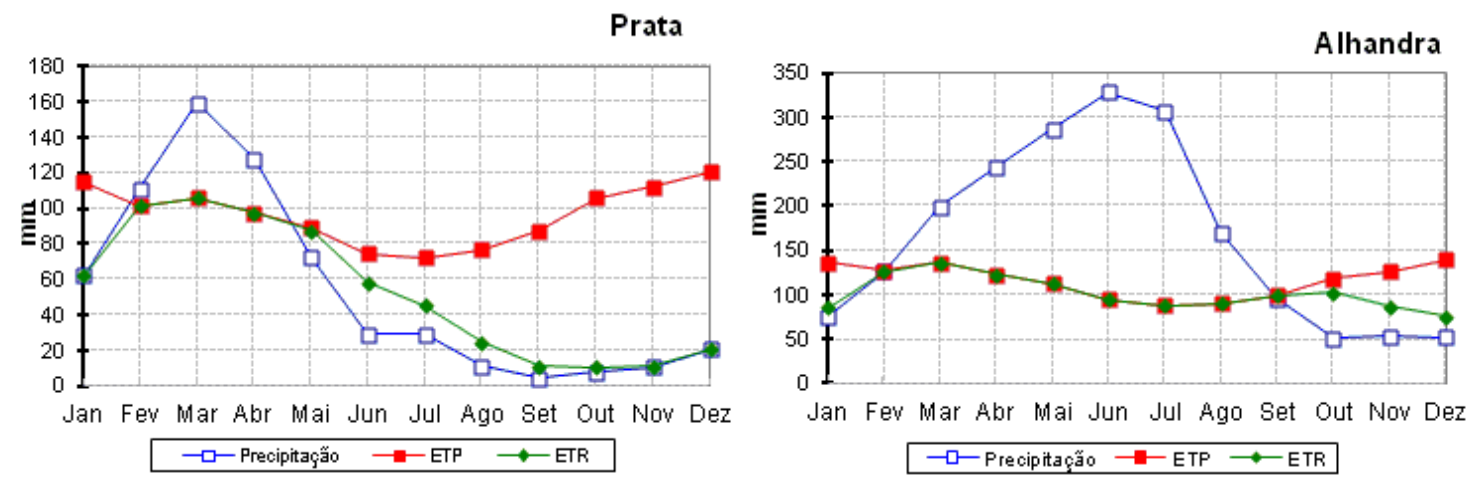

Figura 4 - Representação gráfica da P, ETP e ETR em mm, para os municípios Prata e Alhandra. 
Rossato et al., (2004) constataram que em quase todo o país, o percentual de armazenamento de água no solo entre os meses de junho e setembro está diretamente relacionado a diminuição da precipitação e aumento da ETP. Ou seja, quanto maior a quantidade de água disponível maior a evapotranspiração.

O extrato do BHC para as duas regiões estudadas estão apresentadas na Figura 5, na qual é possível perceber diferença de comportamento entre as regiões. A análise do BHC mostrou que o período úmido $(\mathrm{P}-\mathrm{ETP}>0$ ) na região de Alhandra concentrou-se nos meses de março a agosto (Tabela 2), com maior valor em junho de $234 \mathrm{~mm}$. Enquanto os períodos de déficit hídrico neste município foram durante cinco meses (outubro a fevereiro), como mostrado na Figura 4, possuindo um máximo de déficit na ordem de $-64 \mathrm{~mm}$ no mês de dezembro. E excesso hídrico observado em cinco meses (abril a agosto). Analisando o BHC no município de Prata, observa-se que o período úmido concentrou-se nos meses de fevereiro a abril (Figura 5). Com maior valor no mês de março em torno de $53 \mathrm{~mm}$. Neste município, foram nove meses (maio a janeiro) de déficit hídrico, com valor máximo encontrado no mês de novembro (Tabela 1). E excesso hídrico apenas no mês de abril, no valor de $8 \mathrm{~mm}$.
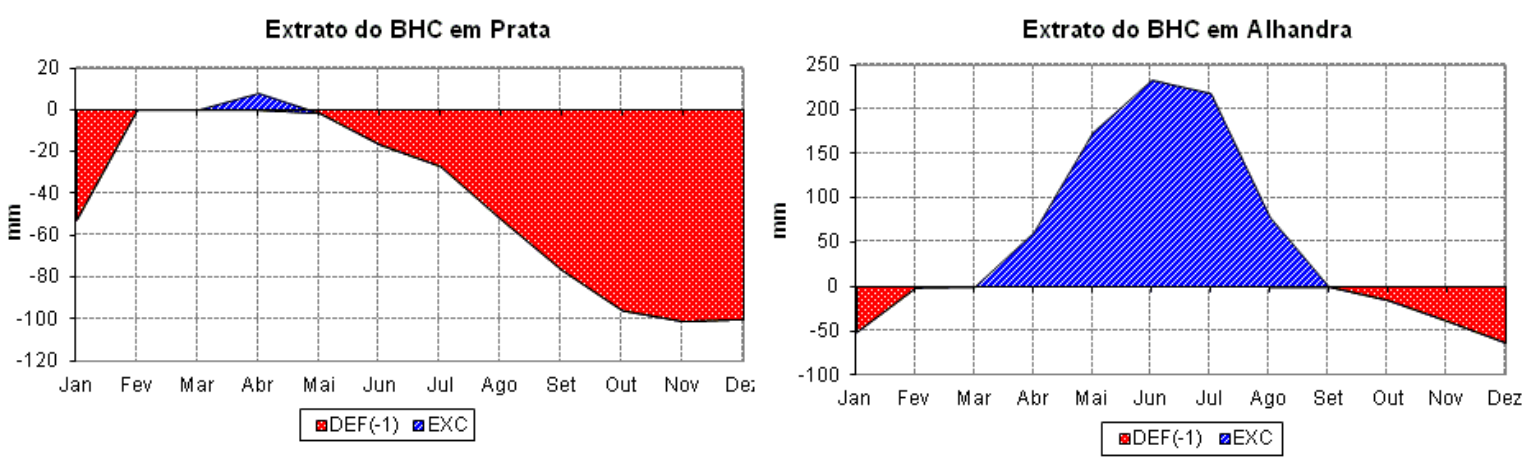

Figura 5. Extrato do BHC em $m m$ para os municípios de Prata e Alhandra.

De maneira geral, o BHC apresentou o mesmo comportamento das chuvas, em que nos meses mais chuvosos o excedente hídrico é maior, sem ocorrência de déficit hídrico. Os dados de BHC são de suma importância para se determinar a época mais apropriada ao longo do ano para o preparo do solo, semeadura e plantio, época e quantidade de água necessária para irrigação, além de identificar nas áreas agricultáveis aquelas que precisam de drenagem e qual a época mais adequada (NEVES et al., 2011).

Tanto o déficit hídrico quanto o excedente podem afetar negativamente o desenvolvimento das culturas. Guarienti et al., (2005), observaram que o excesso de precipitação afetou negativamente o rendimento de grãos da cultura do trigo. Os maiores prejuízos são causados principalmente nas fases de florescimento e maturação, em que na primeira é a fase de maior demanda hídrica pelas culturas e o déficit hídrico prejudica a formação dos frutos e a segunda quando há ocorrência de precipitações elevadas afeta a maturação acelerando o processo de degradação dos frutos e aumento de incidência de patógenos, diminuindo as características qualitativas e quantitativas finais da produção.

O excesso ou falta de água afeta o sistema solo-planta-atmosfera e reduz a produtividade da cultura, através do conhecimento do comportamento do balanço hídrico pode-se realizar um planejamento para implantação de culturas irrigadas nos meses de déficit hídrico. $\mathrm{O}$ 
conhecimento dos períodos em que há maior disponibilidade hídrica para as culturas é de grande importância, pois permitem adequar as épocas de cultivo com os estádios de desenvolvimento em que as culturas mais necessitam de água. Segundo (Santos e Carlesso, 1998) a deficiência hídrica é responsável por alterações no comportamento dos vegetais e sua intensidade e frequência são os fatores que determinam a limitação ao cultivo.

Tabela 1. BHC para o município de Prata/PB.

\begin{tabular}{ccccccccc}
\hline Meses & T & $\mathbf{P}$ & ETP & P-ETP & ARM & ETR & DEF & EXC \\
& ${ }^{\circ} \mathrm{C}$ & $m m$ & $m m$ & $m m$ & $m m$ & $m m$ & $m m$ & $m m$ \\
\hline & & & & & & & & \\
Jan & 24,6 & 62,4 & 114,94 & $-52,5$ & 0,07 & 62,5 & 52,4 & 0,0 \\
Fev & 24,2 & 110,9 & 101,47 & 9,4 & 9,50 & 101,5 & 0,0 & 0,0 \\
Mar & 23,8 & 159,4 & 106,04 & 53,4 & 62,86 & 106,0 & 0,0 & 0,0 \\
Abr & 23,5 & 127,8 & 97,72 & 30,1 & 85,00 & 97,7 & 0,0 & 8,0 \\
Mai & 22,7 & 72,6 & 89,13 & $-16,5$ & 69,98 & 87,6 & 1,5 & 0,0 \\
Jun & 21,6 & 29,3 & 74,83 & $-45,6$ & 40,94 & 58,3 & 16,5 & 0,0 \\
Jul & 21,1 & 29,2 & 72,40 & $-43,2$ & 24,63 & 45,5 & 26,9 & 0,0 \\
Ago & 21,5 & 11,4 & 76,77 & $-65,4$ & 11,42 & 24,6 & 52,1 & 0,0 \\
Set & 22,7 & 4,3 & 87,63 & $-83,4$ & 4,28 & 11,4 & 76,2 & 0,0 \\
Out & 23,9 & 7,8 & 106,30 & $-98,5$ & 1,34 & 10,8 & 95,5 & 0,0 \\
Nov & 24,5 & 10,5 & 112,18 & $-101,7$ & 0,41 & 11,5 & 100,7 & 0,0 \\
Dez & 24,7 & 20,6 & 120,60 & $-100,0$ & 0,13 & 20,9 & 99,7 & 0,0 \\
\hline Totais & $\mathbf{2 7 8 , 9}$ & $\mathbf{6 4 6 , 3}$ & $\mathbf{1 1 6 0 , 0 2}$ & $\mathbf{- 5 1 3 , 7}$ & $\mathbf{3 1 1}$ & $\mathbf{6 3 8 , 3}$ & $\mathbf{5 2 1 , 7}$ & $\mathbf{8 , 0}$ \\
Médias & 23,2 & 53,9 & 96,67 & $-42,8$ & 25,9 & 53,2 & 43,5 & 0,7 \\
\hline
\end{tabular}

Tabela 2. BHC para o município de Alhandra/PB.

\begin{tabular}{ccccccccc}
\hline Meses & $\mathbf{T}$ & $\mathbf{P}$ & $\mathbf{E T P}$ & $\mathbf{P - E T P}$ & ARM & ETR & DEF & EXC \\
& ${ }^{\circ} \mathrm{C}$ & $m m$ & $m m$ & $m m$ & $m m$ & $m m$ & $m m$ & $m m$ \\
\hline Jan & 26 & 76 & 136,92 & $-60,8$ & 17,43 & 85,6 & 51,3 & 0,0 \\
Fev & 26 & 126 & 127,19 & $-1,1$ & 17,29 & 126,2 & 1,0 & 0,0 \\
Mar & 26 & 199 & 136,94 & 62,5 & 79,75 & 136,9 & 0,0 & 0,0 \\
Abr & 26 & 245 & 122,85 & 121,7 & 140,00 & 122,8 & 0,0 & 61,4 \\
Mai & 25 & 287 & 112,55 & 174,7 & 140,00 & 112,5 & 0,0 & 174,7 \\
Jun & 24 & 329 & 94,38 & 234,2 & 140,00 & 94,4 & 0,0 & 234,2 \\
Jul & 23 & 307 & 88,07 & 219,0 & 140,00 & 88,1 & 0,0 & 219,0 \\
Ago & 23 & 170 & 90,73 & 78,9 & 140,00 & 90,7 & 0,0 & 78,9 \\
Set & 24 & 96 & 99,17 & $-3,0$ & 137,00 & 99,1 & 0,0 & 0,0 \\
Out & 25 & 50 & 118,45 & $-68,0$ & 84,31 & 103,2 & 15,3 & 0,0 \\
Nov & 26 & 53 & 126,13 & $-73,1$ & 50,03 & 87,4 & 38,8 & 0,0 \\
Dez & 26 & 52 & 139,31 & $-86,8$ & 26,91 & 75,6 & 63,7 & 0,0 \\
\hline Totais & $\mathbf{3 0 1}$ & $\mathbf{1 9 9 1}$ & $\mathbf{1 3 9 2 , 6 9}$ & $\mathbf{5 9 8 , 1}$ & $\mathbf{1 1 1 3}$ & $\mathbf{1 2 2 2 , 6}$ & $\mathbf{1 7 0 , 1}$ & $\mathbf{7 6 8 , 2}$ \\
Médias & 25 & 166 & 116,06 & 49,8 & 92,7 & 101,9 & 14,2 & 64,0 \\
\hline
\end{tabular}




\section{CONCLUSÕES}

Os resultados mostraram grande variação no total pluviométrico anual nos dois municípios. O período úmido concentra-se nos meses de (março a agosto) em Alhandra e de (fevereiro a abril) em Prata, sendo responsável por mais de $50 \%$ do total pluviométrico anual nos dois cenários.

Perante os resultados obtidos do BHC, o município de Prata em especial, apresentou limitações dos recursos hídricos. Para tanto, é importante atentar para as consequências que os nordestinos, em especial os pratenses, poderão enfrentar grande impacto nas reservas hídricas (corpos hídricos superficiais e no lençol freático) assim como, aumento na evaporação, ressecamento nos solos e a salinização.

Assim, é importante frisar que o município de Prata será insuficiente em atender às necessidades básicas do solo, da vegetação e da sociedade, pois como a região apresentou nove meses de deficiência hídrica no solo, demonstra que para se garantir altas produtividades e qualidade da produção agrícola há a necessidade de um planejamento integrado dos recursos hídricos para a implantação do uso de sistemas de irrigação segundo o critério de maior deficiência ou de maior demanda.

\section{AGRADECIMENTOS}

Os autores agradecem a UACA/UFCG pelo apoio dos dados meteorológicos e a EMBRAPA da unidade de Recife pela disponibilidade dos dados de máxima capacidade de retenção de água disponível pelo solo. E também a CAPES (Coordenação de Aperfeiçoamento de Pessoal de Nível Superior) e CNPQ (Conselho Nacional de Desenvolvimento Científico e Tecnológico) pela ajuda de custo para o desenvolvimento desta pesquisa.

\section{REFERÊNCIAS BIBLIOGRÁFICAS}

ALBRECHT, J.M.F.; LIMA, M.C.; ALBUQUERQUE, F.; SILVA, V.S.M. Influência da temperatura e do tipo de substrato na germinação de sementes de cerejeira. Revista Brasileira de sementes, v. 8, n. 1, p. 49-55, 1986.

ALBUQUERQUE, F.A.; ALMEIDA, L.S.; SANTOS, F. R. ; CAVALCANTI, R. W. G.; LUCENA, A. M. A. Entomofauna associada ao cultivo de algodão agroecológico em duas microrregiões do Semiárido Paraibano, com ênfase em Coleoptera - Campina Grande : Embrapa Algodão, 2012.

CAVALCANTI, E. P.; SILVA, E. D. Estimativa da temperatura de ar em função das coordenadas locais. In: VIII Congresso Brasileiro De Meteorologia Latino Americano e Ibérico, Anais: A meteorologia na prevenção dos desastres Naturais, Belo Horizonte, v.1, p. 154-157, 1994.

CAVALCANTI, E. P.; SILVA, V. P. R; SOUZA, F. A. S. Programa computacional para a estimativa da temperatura do ar para a região Nordeste do Brasil. Revista Brasileira de Engenharia Agrícola e Ambiental, Brasil, v. 10, p. 140-147, 2006.

DIAS, M.A.; LOPES, J.C.; NETO, J.D.S.; HERBELE, E. Influência da temperatura e substrato na germinação de sementes de Jabuticabeira (Myrciaria cauliflora Berg.). IDESIA, v. 29, n. 1 p. 23.27, 2011.

GUARIENTI, E.M.; CIACCO, C.F.; CUNHA, G.R.; DEL DUCA, L.J.A.; CAMARGO, C.M.O. Efeitos da precipitação pluvial, da umidade relativa do ar e de excesso hídrico do solo no 
peso do hectolitro, no peso de mil grãos e no rendimento de grãos de trigo. Ciência e Tecnologia de Alimentos, Campinas, v. 25, n. 3, p. 412-418, 2005.

FENNER, W.; MOREIRA, P.S.P.; FERREIRA, F.S.; DALLACORT, R.; QUEIROZ, T.M.; BENTO, T.S. Análise do balanço hídrico mensal para regiões de transição de CerradoFloresta e Pantanal, Estado de Mato Grosso. Acta Iguazu, Cascavel, v.3, n.1, p. 72-85, 2014. HEINEMANN, A. B.; STONE, L. F. Efeito da deficiência hídrica no desenvolvimento e rendimento de quatro cultivares de arroz de terras altas. Pesquisa Agropecuária Tropical, Goiânia, v. 39. n. 2, p. 134-139, 2009.

KRISHNAN, A. Agroclimatic classification methods and their application to India. In: International Crops Research Institute for the Semi-Arid Tropics: Climatic classification: a consultants' meeting, 14-16, p. 59-88, 1980.

LIMA, P.J. \& HECKENDORFF, W.D. Climatologia. In: GOVERNO DO ESTADO DA PARAÍBA. Secretaria de Educação. Universidade Federal da Paraíba. Atlas Geográfico do Estado da Paraíba. João Pessoa, Grafset. p.34-43, 1985.

MARINI, P.; MORAES, C. L.; MARINI, N.; MUNT DE MORAES, D.; AMARANTE, L. Alterações fisiológicas e bioquímicas em sementes de arroz submetidas ao estresse térmico. Revista Ciência Agronômica, Fortaleza, v. 43, n. 4, p. 722-730, 2012.

MOLION, L. B.; BERNARDO, S. O. Uma revisão da dinâmica das chuvas no Nordeste Brasileiro. Revista Brasileira de Meteorologia, v.17, n.l, p.1- 10, 2002.

MONTEIRO, C. A. de F. Clima e excepcionalismo: Conjecturas sobre o desempenho daatmosfera como fenômeno geográfico. Florianópolis. Ed.UFCS, 1991, p. 1-233.

NETO, JOÃO M.; BARBOSA, MARX P.; DE ARAÚJO, ALEXANDRE E. Efeito dos eventos ENOS e das TSM na variação pluviométrica do semi-árido paraibano. Revista Brasileira de Engenharia Agrícola Ambiental, v. 11, n. 1, p. 61-66, 2007.

NEVES, S.M.A.; NUNES, M.C.M.; NEVES, R.J. Caracterização das condições climáticas de Cáceres/MT Brasil, no período de 1971 a 2009: subsídio às atividades agropecuárias e turísticas municipais. Boletim goiano geografia, Goiânia, v. 31, n. 2, p. 55-68, 2011.

NICHOLSON, S. E. Progress physical geography. In: Sistemas de alerta temprana para casos de sequía y desertificación. OMM-n.906, Genebra, 12p, 1999.

NOAA. Disponível: http://www.cpc.noaa.gov/data/indices/index.html, acesso em: Agosto de 2013.

PEREIRA, A.R.; ANGELOCCI, L.R.; SENTELHAS, P.C. Agrometeorologia: fundamentos e aplicações práticas. Guaíba: Agropecuária, p. 478, 2002.

REICHARDT, K. A água em sistemas agrícolas. Barueri (SP): Manole, 1990.

ROLIM, G. S.; SENTELHAS, P. C.; BARBIERI, V. Planilhas no ambiente EXCEL para os cálculos de balanços hídricos: normal, seqüencial, de cultura e de produtividade real e potencial. Revista Brasileira de Agrometeorologia, Santa Maria, v.6, p.133- 137, 1998.

ROSSATO, L. ALVALÁ, R. C. S.; TOMASELLA, J. Variação espaço-temporal da umidade do solo no Brasil: análise das condições médias para o período de 19711990. Revista Brasileira de Meteorologia, v. 19, n. 2, p. 113-122, 2004. 
SANTOS, R.F.; CARLESSO, R. Déficit hídrico e os processos morfológico e fisiológico das plantas. Revista Brasileira de Engenharia Agrícola e Ambiental, Campina Grande, v. 2, n. 3, p. 287-294, 1998.

SANTOS, G.O.; HERNANDEZ, F.B.T.; ROSSETTI, J.C. Balanço hídrico como ferramenta ao planejamento agropecuário para a região de Marinópolis, Noroeste do Estado de São Paulo. Revista Brasileira de Agricultura Irrigada, Fortaleza, v. 4, n. 3, p. 142-149, 2010.

SCHNEIDER, H. ; SILVA, C. A. O uso do modelo box plot na identificação de anos-padrão secos, chuvosos e habituais na microrregião de Dourados, Mato Grosso do Sul. In: XENANPEGE, 2013, Campinas (SP). X-ENANPEGE: Geografias, Políticas Públicas e Dinâmicas Territoriais. Dourados (MS): Editora da UFGD, 2013. v. 1. p. 9122-9133.

THORNTHWAITE, C.W. An approach toward a rational classification of climate. Geographical review, v. 38, n. 1, p. 55-94, 1948.

THORNTHWAITE, C.W.; MATHER, J.R. Instructions and Tables for Computing Potential Evapotranspiration and Water Balance. Publications in Climatology, v.10, n.3. Drexel Institute of Technology, Centerton, 1957. 